\title{
Treatment of Internal Cylindrical Surfaces by Smoothing and Rolling with the Heat
}

\author{
Vladimir Kotelnikov, Alla Koshurina, Gennady Gavrilov and Dmitriy Chernyshov \\ 603950, Russia, Nizhny Novgorod, Minina street, 24, NNSTU named after R.E. Alekseev
}

\begin{abstract}
Treatment of vnutrennih cylindrical surface plastic deformation is widely used in industry for the production of a large range of engineering products. In the processing method of burnishing of internal cylindrical surfaces of the steel bushings on the lathe-cutting machine with heating revealed that the roughness of the processed surface depends mainly on temperature and is almost independent of the processing speed. The result is a sealing material that improves the quality of the products. The degree of compaction depends on the amount of effort that is applied to the surface of the instrument.
\end{abstract}

Keywords-structural steel; plastic deformation; roll forming; smoothing; surface roughness; heating and microstructure of the steel

\section{INTRODUCTION}

Cold work is characterized by formation of a large number of micro-cracks of various sizes on the surface of the finished workpiece. The cause of the macro-cracks formation in the surface layer is a plastic deformation of the metal at the root of the chip when cutting.

\section{COLD PLASTIC PROCESSING OF METALS}

\section{A. Cold Cutting}

Fragments of the cut layer located at a distance from the line of the plastic flow $\mathrm{CB}$ of metal in the root of the chips are strain-free and move towards the instrument at a certain speed. As approaching the cutting tool the strains in these microvolumes will increase.

When the strain reaches the elastic limit value, the particles of the micro-volumes start to deform plastically. Each of them receives plastic displacement from the action of the cutting tool wedge and changes its direction of motion. In this case, the metal deformation takes place (volume $\mathrm{ABCD}$ deforms in volume EBCN). See Figure 1.



FIGURE I. SCHEME OF THE IMPACT OF THE CUTTING TOOL WEDGE ON THE METAL WHILE CUTTING [1]

\section{B. Maintaining the Integrity of the Specifications}

The template is used to format your paper and style the text. All margins, column widths, line spaces, and text fonts are prescribed; please do not alter them. You may note peculiarities. For example, the head margin in this template measures proportionately more than is customary. This measurement and others are deliberate, using specifications that anticipate your paper as one part of the entire proceedings, and not as an independent document. Please do not revise any of the current designations.

As a result of this deformation occurs separation of the part of metal from the workpiece. The thickness of the metal incoming on the cutting wedge "a" in the separated chip due to the plastic shear changes to $\Delta \mathrm{S}$. The angle formed by a line of plastic flow of the metal particles and the direction of incoming of the metal on the cutting tool is called shear angle and is indicated in Figure 1 by the Greek letter $\beta$ (beta).

If we represent the transition zone of the plastic deformation in the form of a parallelogram ABCD (Figure 1), and the slip lines are considered to be direct, then this zone shear will be by the value of $\triangle x$.

The $\Delta S$ value corresponds to the distance by which the upper side of the square moves in relation to the lower side, and is called the absolute shear. In the theory of plastic deformation characteristics of shear intensity the value of $\varepsilon$ is used, which is called the relative shear.

It equals to the ratio of the absolute shear $\Delta \mathrm{S}$ to the thickness of the layer $\Delta \mathrm{L}$, that underwent this shear, i.e $\varepsilon=\Delta \mathrm{S}$ $/ \Delta$ L. Geometrically $\varepsilon$ is equal to the tangent of the angle $\psi$ of side of the square inclination to the axis z, i.e. $\varepsilon=\operatorname{tg} \psi$.

The element of the cut layer ABCD under the action of the cutting tool wedge is deformed and takes the shape of the parallelogram $\mathrm{EBCN}$.

In the triangle $\mathrm{CDN}-\mathrm{DN}=\Delta \mathrm{x} ;<\mathrm{CND}=90^{\circ} ;<\mathrm{CDN}=\psi=$ $\gamma ;<\mathrm{NCD}=\beta$;

$$
\mathrm{NE}=\Delta \mathrm{S} ; \varepsilon=\Delta \mathrm{S} / \Delta \mathrm{x}=\mathrm{NE} / \mathrm{EA}=\operatorname{ctg} \beta+\operatorname{tg}(\beta-\gamma) .
$$

Analysis of the formulas (1) shows that to determine the relative shear at a certain angle $\gamma$ it is necessary to know the angle of shear. It can be determined by the length of the chips. When moving the tool on $\Delta 1$ the chips length will be $\triangle$ ls. From $\triangle A B E$ 
(Figure 1)

$\Delta l c . / \sin \beta=\Delta l / \sin \delta=\Delta l / \cos (\beta-\gamma)$ и $\Delta l / \Delta l c=\cos (\beta$ $-\gamma) / \sin \beta$.

Relation $\Delta \mathrm{l} / \Delta l c=K l$ was called the shrink-off:

$$
\mathrm{Kl}=\cos (\beta-\gamma) / \sin \beta
$$

This formula is called I. A. Thieme's formula. It shows the relationship between the shrinkage of chips and shear angle $\beta$, as it reflects the condition of continuity of this material (the chips).

Thus the relative shear during cutting depends on the shear angle $\beta$ and a rake angle $\gamma$. The angle $\beta$ can be determined using $\gamma$. In fact $\varepsilon=2 \ldots 5$. We define, for which $\beta$ the relative shift will be minimal. For this we take the first derivative of the equation (3), set it equal to zero and solve the equation with respect to $\beta$ :

$$
\mathrm{d} \varepsilon / \mathrm{d} \beta=-\operatorname{cosec}^{2} \beta+\sec ^{2}(\beta-\gamma)=0 .
$$

This condition is valid for $\beta=90^{\circ}-(\beta-\gamma)$. Then

$[\beta]_{\varepsilon \rightarrow \min }=45^{\circ}+\gamma / 2$. Knowing the relative shear, it is possible to determine the rate of deformation $\left(\mathrm{c}^{-1}\right)$, which represents the ratio of the maximum principal deformation

$\varepsilon_{\text {max }}$ to its length $\tau_{\text {деф }}$ per time unit i.e. $\mathrm{V}_{\text {деф }}=\varepsilon_{\text {max }} / \tau_{\text {деф. }}$.

The temperature which arises as a result of the work of the cutting tool on the metal shear in the root of metal chips depends on the strain rate. The most severe plastic deformation occurs in a narrow band whose width is taken as $\Delta \mathrm{x}$. The deformation is determined by the formula:

$$
\begin{array}{r}
\tau_{\text {дер }}=\Delta x / \Delta V_{c}=\left(\Delta x \cdot K_{l}\right) / V \text { т.е. } \\
\text { Удеф } \quad \mathrm{V} / \quad \text { х } \quad \mathrm{Kl}
\end{array}
$$

The strain rate is very high when cutting. According to [1], in the treatment of structural steels of normal quality $\Delta x=0$, $02-0,005 \mathrm{~mm} ; \varepsilon=2-5 ; \mathrm{KI}=2.0-4.0$. At a cutting speed of 60 $\mathrm{m} / \mathrm{min}=100 \mathrm{~cm} / \mathrm{sec}$ the strain rate equals Vdef $=4000 \mathrm{c}^{-1}$.

High strain rates do not allow us to establish a clear distinction between fragile and plastic materials, as the same material depending on the nature of the stress state at cutting strain rates may behave differently.

The deformation of the metal at the root of the chip continues to the moments of rupture of crystals under the pressure of the cutting wedge. Separation and subsequent shear along the slide line form the chip configuration, and at the place of removal the metal strains arise in the surface layer of the finished part, which leads to formation of the rupture micro-cracks of discontinuity of metal.

\section{Metal Forming with Heating}

In order to reduce the number of micro-cracks in the metal of the surface layer after cold treatment the hollow cylindrical long workpieces are rolled by roll burnishing and subjected to spraying with wear-resistant and heat-resistant materials[2]. The process of cold plastic deformation of the cylindrical inner side of the hollow workpieces is characterized by improvement of quality indicators through falling of roughness peaks into holes[3]. Force impact on the cold surface always leads to opening and growth of micro- cracks. Practice shows that the cold surface - plastic treatment does not eliminate appearance of fire cracking.

The preliminary flat steel sample was milled to create micro-cracks in the surface layer of the rupture micro-cracks. Then the plate was subjected to surface plastic deformation by roll burnishing[4].

After treatment by SPD (surface plastic deformation) a run-sectional sample workpiece was cut from one end of the rolled plates. This sample workpiece was cut into halves. In its first half we measured micro-hardness of the surface layer after cold rolling and milling. In its second half the end surface of the sample was subjected to grinding and polishing for determining the presence of micro-cracks in the surface layer metal by the method of micro-structural analysis.

At the remaining portion of the flat workpiece we milled the chamfer for free entrance of the roller to the surface. The plate prepared like this was subjected to SDP (surface plastic deformation) with heating. The process of rolling the heated steel workpiece was also made on the longitudinal planing machine.

At the end of the roller motion we installed a gutter filled with water. When passing through the water-filled gutter the roller was cooled down. Before carrying out SDP (surface plastic deformation) the surface of the workpiece was heated with the gas flame up to a temperature of $550-700{ }^{\circ} \mathrm{C}$. The workpiece was rolled over several times along the surface of the heated metal.

After cooling we cut from the worpiece rolled by hot method a cross-cut sample for the study of the changes in the surface layer. The sample was cut from the flat plate treated with heat in the middle of the roll burnisher. A cross section of the sample was subjected to grinding and then to polishing.

Metallurgical studies were carried out directly in the surface layer of the milled rolled metal. The butt ends of both bands of the sample were studied at three points: at the edge of the surface, the center of the band of milling or rolling and from the other end of the band. With an optical microscope KEVENCE - 1000 we analyzed the metal microstructure in the surface layer. The photo of the metal structure of the surface after: milling (a), s PD with heating (B) and cold SPD is shown in Figure 2.

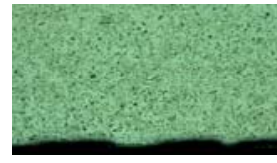

a

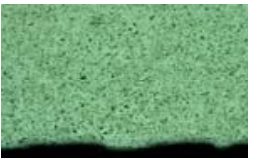

b

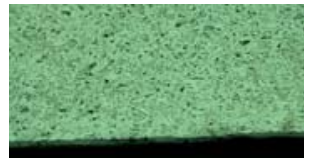

C
FIGURE II. THE MICROSTRUCTURE OF THE SURFACE LAYER OF METAL AFTER MILLING (A) AFTER SPD WITH HEATING (B) AND AFTER COLD SDP (C) X200 
Comparing the structure of the surface layer after milling (Figure 2 a) and treatment of the surface after SPD with heating (Figure $2 \mathrm{~b}$ ) we can see that the heating increases the size of the metal grains. The surface of the milled metal is coated with tabs of the cutting tool output and the surface is flat after heating with SPD. On the milled surface, there are traces of micro-cracks formed as a result of plastic deformation of cold metal at the chips root. In the surface layer, rolled with heating there are nosimilar micro-cracks. As a result of the comparative analysis of the metal structure, we can conclude that during SPD of the heated metal micro-cracks are closed throughout the depth of the surface layer.

Comparing the structure of the surface layer of the steel plate, rolled with heating (Figure $2 \mathrm{~b}$ ), and treated with cold SPD (Figure $2 \mathrm{c}$ ), it is noted that when micro-cracs at cold rolling are not closed. After cold SPD compression of the surface layer is not observed. The difference of the plate thickness, rolled with heating and without heating, is $0.02 \mathrm{~mm}$. It also shows the compaction of the surface layer after rolling heated to the temperature of the metal softening.

The process of surface plastic deformation of the metal heated by a gas burner to a temperature of $550-650^{\circ} \mathrm{C}$, by rolling of the cylindrical inner side, was also carried out on screw-cutting lathe with clamp of the sleeve in the chuck jaws of the machine. The shank of the roll burnisher was clamped in the tool holder of the cross-feed carriage so that the axis of the roll burnisher was in the in the plane of the sleeve axial section

The degree of roughness was measured on the inner side of the cut sleeve after its cooling. The modes of rolling of the heated surface of the sleeve were chosen to be identical to the parameters of cold rolling used in machine building (Table 1).

TABLE I. MODES OF ROLLING WITH SURFACE HEATING

\begin{tabular}{|l|l|l|l|l|l|l|}
\hline № & $\begin{array}{l}\text { Tempera } \\
\text { ture of } \\
\text { the inner } \\
\text { side }{ }^{\circ} \mathbf{C}\end{array}$ & $\begin{array}{l}\text { Roughne } \\
\text { ss before } \\
\text { rolling, } \\
\text { micron }\end{array}$ & $\begin{array}{l}\text { Rolling } \\
\text { force, } \\
\mathbf{N}\end{array}$ & $\begin{array}{l}\text { Spindle } \\
\text { speed, } \\
\text { rpm }\end{array}$ & $\begin{array}{l}\text { The } \\
\text { feed } \\
\text { rate, } \\
\text { mm/ro } \\
\text { t }\end{array}$ & $\begin{array}{l}\text { Roughn } \\
\text { ess after } \\
\text { rolling, } \\
\text { micron }\end{array}$ \\
\hline 1 & 20 & 12.5 & 3760 & 30 & 0.28 & 3.2 \\
2 & 20 & $-\ll-$ & 3690 & 60 & 0.28 & 3.2 \\
3 & 20 & $-\ll-$ & 3770 & 120 & 0.28 & 3.2 \\
\hline 4 & 500 & 12.5 & 1440 & 30 & 0.28 & 1.25 \\
5 & $-\ll-$ & $-\ll-$ & 1480 & 60 & 0.28 & 1.25 \\
6 & $-\ll-$ & $-\ll-$ & 1470 & 120 & 0.28 & 1.25 \\
\hline 7 & 550 & 12.5 & 1210 & 30 & 0.28 & 1.0 \\
8 & $-\ll-$ & $-\ll-$ & 1230 & 60 & 0.28 & 1.0 \\
9 & $-\ll-$ & $-\ll-$ & 1320 & 120 & 0.28 & 1.0 \\
\hline 10 & 600 & 25.0 & 1160 & 30 & 0.28 & 0.8 \\
11 & $-\ll-$ & $-\ll-$ & 1180 & 60 & 0.28 & 0.8 \\
12 & $-\ll-$ & $-\ll-$ & 1150 & 120 & 0.28 & 0.8 \\
\hline
\end{tabular}

As we can see from the results of measurement, the roughness of the surface treated by rolling essentially depends on the heating temperature and is practically independent from the treatment speed. Compared to cold rolling, rolling with heating gives better results for the roughness of the treated surface.

As the results of the metallographic analysis show, roll forming with heating temperatures of $350-450{ }^{\circ} \mathrm{C}$ is not accompanied by compaction of the surface layer. Heating to temperatures well above $550-650{ }^{\circ} \mathrm{C}$ leads to compaction and smoothing of the micro-cracks remaining after cold machining in the surface layer of the treated material. The degree of compaction during rolling depends on the force applied to the surface by the roll burnisher.

\section{Processing of the Holes by Burnishing the Inner Side of the Holes in the Steel}

The authors tested and investigated the treatment of the holes by burnishing the inner side of the holes in the steel sleeves during their rotation on the screw-cutting lathe with heating. The value of the tension was determined taking into account the linear expansion of the hole, depending on the metal temperature. The diameter of the calibrating band of the planishing hammer $\mathrm{D}=20 \mathrm{~mm}$ was chosen so as to ensure collapse of the surface layer of the heated metal to a depth $\mathrm{i}=$ $(0.02-0.10) \mathrm{mm}$ on the cylindrical inner side.

During the experiments, the value $i$ varies from 0.6 to 0.1 $\mathrm{mm}$. It turned out that for small values of $\mathrm{i}$ only high parameters of roughness are reduced and inaccuracies of the manufactured mold are partially eliminated. For large values of $i$ the inner and outer diameter of the sleeve increases [1].

We distinguish the elementary volume of a deformable metal sleeve in its contact area with the cone of the planishing hammer, cm. Figure 2.



FIGURE III. DIAGRAM OF THE FORCES DEFORMING THE METAL IN THE ELEMENTARY VOLUME, WHERE:

The force $\mathrm{P}$, acting on the planishing hammer, arises deformation resistance response in the contact area of the cone of a rotating metal sleeve:

Sy - metal shear resistance force in the perpendicular direction along the axis $\mathrm{OY}$, under the impact of the pressure force of the cone that equals to $\mathrm{P} \operatorname{tg} \beta$,

Sz- metal deformation resistance force directed along the axis OZ, due to the action of the tangential friction forces arising from the cone friction during rotation of the sleeve.

Under the impact of $\mathrm{Sx}$, aroused from force $\mathrm{P}$ of the pressure of the planishing hammer, the metal grain at point $\mathrm{O}$, heated to a temperature of $400-600^{\circ} \mathrm{C}$, will shift towards the 
direction of the axis $\mathrm{OX}$, deforming and shifting the adjacent grains, heated to the same temperature. Simultaneously, the same grain from the point $\mathrm{O}$ will shift along the axis $\mathrm{OY}$ by the force $P \operatorname{tg} \beta$ interacting with the stronger and less heated grains. This leads to stretching and flattening of the grain along the axis $\mathrm{OZ}$ under the influence of tangential force $\mathrm{Sz}$.

As a result of these displacements, the elongated metal grain will be in a shifted position perpendicular to the summing force $\mathrm{S} \Sigma$. Such position of the metal grains elongated at an angle to the axis of the sleeve creates the compacted surface layer and reduces formation possibility of longitudinal cracks in the treated hole.

The results of burnishing with heating of the inner side of the sleeve $\mathrm{Dbn}=51.3 \mathrm{~mm}$ at the heating temperature in Theat $=600-800^{\circ} \mathrm{C}$, with a diameter of the calibrating cone (cone material P6M5) of the planishing hammer $20 \mathrm{~mm}$ are shown are in Tables 1, 2.

TABLE II. THE RESULTS OF BURNISHING THE CYLINDRICAL INNER SIDE OF THE SLEEVE MADE FROM 40X STEEL WITH WALL THICKNESS OF 10MM.

\begin{tabular}{|c|c|c|c|c|c|c|c|}
\hline № & $\begin{array}{l}\mathrm{n}, \mathrm{rp} \\
\mathrm{m}\end{array}$ & $\begin{array}{l}\mathrm{S}, \\
\mathrm{mm} / \mathrm{rot}\end{array}$ & $\begin{array}{l}\mathrm{D}_{\text {bn }}{ }^{\mathrm{N}}, \\
\mathrm{mm}\end{array}$ & $\begin{array}{l}\mathrm{T}_{\text {heat }} \text {, } \\
{ }^{\circ} \mathrm{C}\end{array}$ & $\begin{array}{l}\text { Px, } \\
\mathrm{H}\end{array}$ & $\begin{array}{l}\mathrm{D}_{\mathrm{bn}}^{2}, \\
\mathrm{~mm}\end{array}$ & $\begin{array}{l}\text { Preload } \\
\text { attitude floats }\end{array}$ \\
\hline 1 & 30 & 0.28 & 51.3 & 800 & 249 & 51.413 & $\mathrm{i}=0.6, \mathrm{~mm}$ \\
\hline 2 & 60 & $-\ll-$ & $-\ll-$ & $-\ll-$ & 263 & 51.426 & $-\ll-$ \\
\hline 3 & 120 & $-\ll-$ & $-\ll-$ & $-\ll-$ & 285 & 51.442 & $-\ll-$ \\
\hline 4 & 30 & 0.28 & 51.3 & 700 & 431 & 51.373 & $\mathrm{i}=0.5, \mathrm{~mm}$ \\
\hline 5 & 60 & $-\ll-$ & $-\ll-$ & $-\ll-$ & 444 & 51.380 & $-\ll-$ \\
\hline 6 & 120 & $-\ll-$ & $-\ll-$ & $-\ll-$ & 465 & 51.397 & $-\ll-$ \\
\hline 7 & 30 & 0.28 & 51.3 & 600 & 856 & 51.329 & $\mathrm{i}=0.4, \mathrm{~mm}$ \\
\hline 8 & 60 & $-\ll-$ & $-\ll-$ & $-\ll-$ & 867 & 51.335 & $-\ll-$ \\
\hline 9 & 120 & $-\ll-$ & $-\ll-$ & $-\ll-$ & 872 & 51.342 & $-\ll-$ \\
\hline
\end{tabular}

Table 2 shows that the process of burnishing with large quantity of heating and tension changes diametrical size of the inner side and compacts the metal (preload value $i=0.6-0,4$ $\mathrm{mm})$.

An important criterion for assessing the effectiveness of burnishing with heating was the change of roughness of the treated surface.

The microstructure of the metal samples after burnishing of the inner side of the sleeve hole is shown in figure (3, a and b). It can be seen that after burnishing with heating there are no micro-cracks in the surface layer. The grains of structural components- pearlite and ferrite are flattened and turned towards the application of forces during burnishing.

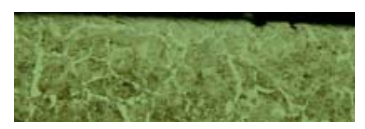

a

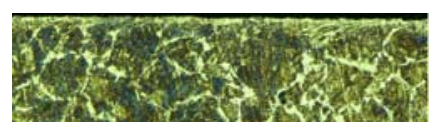

b
FIGURE IV. THE MICROSTRUCTURE OF THE METAL AFTER BURNISHING OF COLD METAL (X500): A) COLD BURNISHING; B) BURNISHING WITH HEATING
Thus, for modes of burnishing with heating of the treated inner holes on the $40 \mathrm{X}$ steel products it is necessary to select the maximum treatment speed and temperature range of heating of the inner side of $500-650^{\circ} \mathrm{C}$. Thus we increase productivity and accuracy and reduce costs.

Treatment of cylindrical inner sides with heated burnishing alters the surface roughness of the treated surfaces that ensures the absence of micro-cracks in the surface layer. This type of treatment leads to is compacted surface layers of metal, resulting in improved durability.

Work performed in the Nizhny Novgorod State Technical University under the agreement No. 14-33-000 32 code "1 Russian Science Foundation - 1" dated 9 September 2014. "The establishment of a joint research laboratory of structural and functional materials for complex technical systems operating in extreme conditions of the Arctic and sub-Arctic climate".

\section{CONCLUSION}

As a result of hot rolling and burnishing of the heated metal in the surface layer of the hole of the hollow cylindrical workpiece micro-cracking does not occur. Depending on the heating temperature of the surface layer the magnitude of deformation resistance decreases, resulting in metal compacted to a depth of $0,025 \mathrm{~mm}$.

The analysis of the microstructure revealed that compaction of the surface layer after rolling and burnishing with heating surfaces of the hollow cylindrical holes is caused by deformation and partial reversal of the microstructure grains of the treated material.

It is found that the process of rolling and burnishing with heating of the inner side of the hollow cylindrical holes may be recommended to replace the cold working, as providing compaction of the surface of the metal layer that makes the surface resistant to emergence of longitudinal cracks during thermal and dynamic impacts.

\section{REFERENCES}

[1] Bobrov V. F. Basics of the theory of metal cutting. M.: Machine building, 1975. - 343 p.

[2] Pyzyrykov F. A. fundamentals of the theory of creation of protective coatings by spraying of metals. M.: Mashinostroenie $2010-406 \mathrm{~S}$.

[3] Smelyanskiy, V. M., Mechanics of hardening by surface plastic deformation. M.: Mashinostroenie $2002-300$ C.

[4] Kotelnikov V.I. Basics of metal cutting with heating / V.I. Kotelnikov; NNSTU named after R.E. Alekseev - N. Novgorod, 2011. - 199 p. 